\title{
Sobre a construção de um léxico da afetividade para o processamento computacional do português
}

\section{A Sentiment Lexicon for Portuguese Natural Language Processing}

\author{
Cláudia Freitas* \\ Pontifícia Universidade Católica \\ Rio de Janeiro / Rio de Janeiro - Brasil
}

\begin{abstract}
RESUMO: O objetivo principal deste artigo é descrever o processo de elaboração de um léxico de elementos afetivos da língua portuguesa e polaridades associadas, construído principalmente para auxiliar a tarefa de análise de sentimento. Buscase, além disso, mostrar como a exploração da dimensão afetiva da linguagem encontra espaço na descrição da língua e pode, ainda, contribuir para o ensino de português como segunda língua. Assim, o léxico foi criado com um duplo objetivo: fornecer subsídios linguísticos para uma aplicação do processamento de linguagem natural (PLN) e contribuir com a caracterização do vocabulário afetivo da língua portuguesa, sobretudo em contextos informais.
\end{abstract}

PALAVRAS-CHAVE: léxico de polaridades; léxico de sentimento; linguística com corpus; análise de sentimento; prosódia semântica; linguística computacional; análise de opinião.

ABSTRACT: The main goal of this paper is to describe the creation of a sentiment lexicon designed to collaborate in sentiment analysis tasks. We also show how the analysis of the affective language finds room in language description and that it can contribute to foreign language teaching as well. Thus, the lexicon was created with a dual purpose: provide a resource for natural language processing tasks and collaborate to the characterization of Portuguese language affective vocabulary, especially in informal contexts.

KEYWORDS: corpus linguistics; polarity lexicon; sentiment lexicon; sentiment analysis; emotional words; semantic prosody; computational linguistics; opinion mining.

*claudiafreitas@puc-rio.br 


\section{Introdução}

Recursos lexicais são reconhecidamente parte fundamental de sistemas que lidam com o processamento computacional da língua, os quais podem ter como objetivo a realização de tarefas relacionadas à identificação e extração da informação contida em textos. Recentemente, tem havido um crescente interesse não apenas na identificação de informações factuais (como quem, $o$ quê, quando, onde etc.), mas também na identificação da informação subjetiva que textos veiculam. A área chamada análise de sentimento ou mineração de opiniāo $^{1}$ busca justamente identificar opiniōes, avaliaçôes e atitudes expressas em texto (PANG; LEE, 2008).

No entanto, para processar informação é preciso informação. Essa informação, cada vez mais, é fornecida por léxicos, que, no âmbito do processamento computacional da língua, se referem ao componente de um sistema que contém informação (semântica e/ou gramatical) sobre palavras ou expressóes, enquanto o termo dicionário, normalmente, remete a objetos (livros impressos ou eletrônicos) destinados a leitores humanos, mas que também podem estar acessíveis a máquinas (GUTHRIE et al., 1996).

Assim, uma das abordagens para a extração automática de sentimento/ opinião toma por base léxicos de emoções/sentimentos, que podem ser gerais, como o SentiWordNet (ESULI; SEBASTIANI, 2006), ou específicos para determinados domínios ou tarefas (RILOFF; WIEBE, 2003; POIRIER et al., 2011). Para o português (variante de Portugal ${ }^{2}$ ), destacamos o SentiLex (SILVA; CARVALHO; SARMENTO, 2012), léxico construído a partir de um corpus composto por comentários (posts) em matérias de jornal sobre política. Tais léxicos contêm, além das classes de palavras, a polaridade associada a cada item, que pode ser positiva, negativa e, em alguns casos, neutra.

\footnotetext{
${ }^{1}$ Como notam Pang e Lee (2008), são variadas as nomenclaturas para os trabalhos que lidam com o tratamento computacional de opinião/sentimento/subjetividade no texto: mineração de opinião (opinion mining); análise de sentimento (sentiment analysis) e análise de subjetividade (subjectivity analysis).

${ }^{2}$ Ainda que no âmbito de léxicos computacionais não seja relevante aludir a diferenças entre variantes, visto que, para a maior parte do processamento da língua, o que é comum é mais importante do que o específico, a diferença é mencionada devido a variações quanto à atribuição de polaridade de algumas palavras/expressôes no SentiLex, não sendo possível saber se tais alteraçôes se devem justamente à variante ou a outro fenômeno. O adjetivo incrivel, por exemplo, comentado na seção 2.1, possui polaridade neutra no Senti-Lex, diferentemente do que é proposto neste artigo.
} 
Palavras ${ }^{3}$ são aglomerados de vários tipos de informação. A informação afetiva, simplificadamente traduzida aqui como polaridade, é mais uma. Considerase que uma dada palavra tem polaridade quando é sistematicamente utilizada para expressar um sentimento sobre algo. Perfeito, admirável e amei são exemplos de palavras com polaridade positiva.

Quanto à forma de elaboração, léxicos com polaridades podem ser construídos manual ou automaticamente, dando-se preferência à maneira automática. No entanto, a criação automática se sustenta (i) em recursos lexicais criados manualmente, como a WordNet (FELLBAUM, 1998) - para a qual não há, até o momento, equivalente em português em termos qualitativos e quantitativos -, ou (ii) em corpora, que podem, por sua vez, ser manual ou automaticamente anotados com informação referente à polaridade.

O objetivo principal deste artigo é descrever o processo de elaboração de um léxico com elementos afetivos da língua portuguesa e polaridades associadas, o ReLi-Lex, criado a partir de um corpus composto por resenhas de livros publicadas na internet e previamente anotado com informação de opinião (FREITAS et al., 2012; 2013). Busca-se, além disso, mostrar como a exploração da dimensão afetiva encontra espaço na descrição da língua e pode, ainda, contribuir para o ensino de línguas estrangeiras. Assim, o léxico foi criado com um duplo objetivo: fornecer subsídios para uma aplicação do processamento de linguagem natural (PLN) e contribuir para a caracterização do vocabulário afetivo da língua portuguesa, sobretudo em contextos informais.

A seção 2 apresenta a perspectiva teórica que norteou a elaboração do léxico, bem como a relação entre afetividade e estudos da linguagem e sua relação com o PLN; a seção 3 descreve o processo de elaboração do léxico e suas características; por fim, a seção 4 traz algumas considerações finais e discute alternativas para a continuação do trabalho.

\section{PLN, léxico e significado: enquadramento teórico}

A partir sobretudo da década de 1990, com a chamada "revolução do corpus", a linguística computacional/Processamento de Linguagem Natural (PLN) se estabelece como área voltada à resolução de problemas práticos, comprometida principalmente com aplicaçóes. Das tarefas que atualmente preocupam o PLN, a que motiva a realização deste trabalho é a análise de sentimento. Paralelamente, ao tratar da formalização de aspectos do significado para o processamento

${ }^{3}$ Utilizo aqui o termo palavra consciente da sua dificuldade de delimitação e conceituação, como discutido em Biderman (2001). 
computacional, é inevitável o diálogo com a semântica, "domínio de investigação de limites movediços" (ILARI; GERALDI, 1985, p. 6).

De forma bastante simplificada, é possível distinguir três paradigmas que irão problematizar o significado de forma sistemática: realista, mentalista e pragmático. Porém, ainda que didaticamente essa distinção seja útil, teorias realistas e mentalistas têm historicamente compartilhado pressupostos teóricos fundamentais, o que permite, com alguma simplificação, agrupá-las sob o rótulo representacionistas ou essencialistas (MARTINS, 2004). Para ambos, a linguagem é um sistema de representaçóes de significados fixos e compartilhados; palavras representam algo (entidades mentais para os primeiros e virtuais para os segundos), e essa relação de representação se dá de maneira objetiva e estável.

Já o ponto de vista pragmático diz respeito à linguagem em uso, em diferentes contextos. Há uma mudança de perspectiva, uma vez que a linguagem passa a ser entendida como uma prática intersubjetiva. Dentre as linhas de investigação pragmáticas, contudo, há as que poderiam ser também enquadradas em um paradigma essencialista. Isso porque se, por um lado, mentalistas irão assumir que é pela análise das propriedades dos códigos de linguagem que será possível explicar a prática da comunicação, algumas correntes da pragmática recomendam a análise das propriedades da prática da comunicação como maneira de fornecer uma explicação do que são as línguas e os significados, o que faz com que esta visão pragmática tradicional possa ser compreendida como uma disciplina complementar a uma visão semântica essencialista (MARTINS, 1999; TAYLOR, 1992).

Porém, a crítica que pragmatistas mais radicais farão é que qualquer análise essencialista da linguagem é impossível, por ser impossível um distanciamento do objeto examinado. A relação entre linguagem e realidade seria forjada, na medida em que a própria linguagem constitui a realidade.

No presente trabalho, assumimos, com Ellis (1993), que palavras são (também) resultados de processos de categorização, guiados por interesses compartilhados por uma cultura/comunidade discursiva e não por fatos do mundo real, os quais rotulariam. Ao invés do rótulo, o relacionamento: palavras relacionam "situaçôes", e grupos de coisas diferentes, ou experiências únicas, formam uma categoria coerente-a categoria "folha", para usar o exemplo nietzschiano ${ }^{4}$ - porque

4 "Assim como é evidente que uma folha não é nunca completamente idêntica à
outra, é também bastante evidente que o conceito de folha foi formado a partir do
abandono arbitrário destas características particulares e do esquecimento daquilo
que diferencia um objeto de outro. O conceito faz nascer a idéia de que haveria na
natureza, independentemente das folhas particulares, algo como a folha, algo como 
nós, membros de uma dada comunidade, fazemos com que eles formem, por meio de estratégias de simplificação e equivalência. $\mathrm{O}$ que de modo algum equivale a afirmar que não existam similaridades entre as coisas, mas não parece que essas sejam a única base para as categorias de uma língua. Assim, situações que não são exatamente as mesmas são categorizadas como sendo as mesmas. Eé o recorte -a categorização - dependente e articulado com as intenções que traz, por um lado, a estabilidade para que possamos acordar sobre significados, perceber regularidades e, por outro, a instabilidade quando se busca definir precisamente os próprios significados, dado que este não é entendido como intrínseco às palavras.

Com relação ao significado, assumimos, portanto, uma posição alinhada com a perspectiva antiessencialista, segundo a qual significados (dos quais a polaridade é uma das dimensões) correspondem a usos culturalmente determinados que fazemos das palavras. Assim, sobre as regularidades que inegavelmente observamos quanto ao significado (e que subjazem, por exemplo, à elaboração de dicionários), são consequência de ser, o significado, "construído e atribuído a partir de um tácito acordo comunitário" (ARROJO, 1992, p. 37).

Outro aspecto frequentemente associado à elaboração de um léxico que contém informação relativa às polaridades que podem ser atribuídas às palavras em certos contextos é a aproximação com modelos que lidam com a distinção conotativo/denotativo, sendo a polaridade vinculada à conotação. Assumir uma visão antiessencialista, no entanto, é

reconhecer que nenhuma teoria da linguagem conseguiu, até hoje, a partir de pressupostos logocêntricos, distinções objetivas e indiscutíveis entre o literal e o figurado, entre o irônico e o não irônico, ou entre o literário e o não-literário enquanto propriedades textuais intrínsecas. (ARROJO, 1992, p. 36).

A Análise de Sentimento pode ser vista como uma subárea da Extração de Informação que lida com a identificação de opiniōes, avaliações e atitudes com relação a entidades como pessoas, produtos e organizações, expressas textualmente. Estimulada sobretudo pela crescente disponibilidade e diversidade de opinióes

uma forma primordial, segundo a qual todas as folhas teriam sido tecidas, desenhadas, cortadas, coloridas, pregueadas, pintadas, mas por mãos tão inábeis que nenhum exemplar teria saído tão adequado ou fiel, de modo a ser uma cópia em conformidade com o original." (NIETZSCHE, 1911, p. 12). 
em blogs e redes sociais, a tarefa pode assumir diferentes aspectos: da caracterização de documentos (por exemplo, resenhas), como favoráveis ou desfavoráveis relativamente a um dado objeto, até à identificação de pontos de vista em debates políticos, trazendo desafios interessantes tanto do ponto de vista do processamento computacional quanto do ponto de vista linguístico.

Quando criados automaticamente a partir de corpus, léxicos para a análise de sentimento (também chamados de dicionários de polaridades, conforme Taboada et al. [2011]) podem partir de uma lista de "palavras-semente" (seed words), - um grupo pequeno de palavras com uma polaridade forte e estável, como ruim, excelente, péssimo -, usada para expandir listas de palavras, gerais ou dependentes de domínio. Outra alternativa consiste em utilizar bases lexicais preexistentes, como tesauros (MOHAMMAD; DUNNE; DORR, 2009) ou a WordNet, para a criação de léxicos gerais, como a SentiWordNet (ESULI; SEBASTIANI, 2006). No entanto, lembramos que, para o português, não há equivalente para a WordNet em termos de quantidade e qualidade da informação disponibilizada, ainda que algumas tentativas estejam em andamento e que a conjugação de diferentes recursos já existentes para o português apareça como uma alternativa interessante (para uma revisão da literatura sobre recursos lexicais disponíveis para o processamento computacional do português, veja-se Santos et al. [2010]).

Por fim, embora a forma de elaboração manual seja normalmente evitada, devido exclusivamente ao seu alto custo, é aquela que oferece resultados mais confiáveis. De um ponto de vista linguístico, a criação de recursos como léxicos semânticos, de forma manual ou semiautomática, se oferece como uma oportunidade para a observação da língua em ambiente natural, e se feita a partir de corpus, com um imenso potencial para a exploração de fatos da língua - quer do ponto de vista das regularidades, quer das irregularidades. Além disso, como salienta Sampson (2001), o trabalho empírico, de taxonomização, é uma atividade valiosa em si mesma, autorizada pelo compartilhamento de esforços e de recursos, e não uma tarefa desinteressante e trivial, anterior ao trabalho de descobertas sobre a língua.

\subsection{Afetividade e dicionários}

$\mathrm{Na}$ perspectiva linguística, o interesse pela linguagem emotiva ou afetiva tem ocupado posição periférica. Como notam Ochs e Schieffelin (1989), linguistas têm subestimado a atuação de estruturas gramaticais e discursivas para fins afetivos, e a tradição lexicográfica não costuma incluir informação 
chamada "conotativa" sistematicamente nos dicionários, dada, principalmente, sua alta dependência contextual.

Por exemplo, é uma informação relevante do português saber que incrivel (na variante brasileira, pelo menos), é usada para caracterizar positivamente: um ator incrivel, um telefone incrivel ou um restaurante incrivel. A consulta aos dicionários, no entanto, omite essa informação: tanto no Dicionário eletrônico Houaiss quanto na versão on-line do Dicionário Priberam da Lingua Portuguesa, são três as acepções de incrivel. Reproduzo apenas as acepçôes deste último: ${ }^{5}$

1. Que não pode ser acreditado.

2. Extraordinário.

3. Que custa a acreditar.

Para falantes nativos, é fácil perceber que restaurante incrivel equivale a restaurante extraordinário, ambos expressando um sentimento positivo, mas não há nada que forneça essa informação - e sabemos que extraordinário, assim como incrivel, não necessariamente é usado para exprimir um ponto de vista positivo. A consulta a extraordinário, por sua vez, oferece diversas acepçōes, apenas uma delas relacionada ao uso de incrivel que nos interessa: ${ }^{6}$

4. Excessivo; muito grande; descomunal; singular; raro; anormal; assombroso; estupendo.

Novamente, falantes nativos não têm dificuldade para reconhecer que apenas estupendo se assemelha ao incrivel positivo, ainda que assombroso e raro também possam ser usados. Mas, novamente, não há pista no dicionário que nos leve a isso.

Imaginemos agora um dicionário com informação de polaridade. Nesse dicionário, para a palavra incrivel, teríamos a marcação [+] na acepção 2 , extraordinário, indicando que, se alguém me diz que foi a um restaurante incrível, provavelmente é porque o restaurante foi bom e que, também, um restaurante incrivelé, de certa maneira, equivalente a restaurante extraordinário. Supondo que não se saiba o que é extraordinário, a indicação de polaridade em suas diferentes acepções ajudaria a perceber quais termos seriam mais

${ }^{5}$ http://www.priberam.pt/dlpo/default.aspx?pal=incr\%C3\%ADvel

${ }^{6} \mathrm{http}: / / \mathrm{www}$. priberam.pt/dlpo/default.aspx?pal=extraordin $\% \mathrm{C} 3 \% \mathrm{~A} 1$ rio 
apropriados como sinônimos. A FIG. 1 ilustra o caminho percorrido, e ao final poderíamos inferir a relativa equivalência entre um restaurante incrivel, extraordinário, estupendo e admirável - e a inadequação entre a sinonímia de um restaurante incrivel e um restaurante anormal, excessivo ou espantoso. ${ }^{7}$

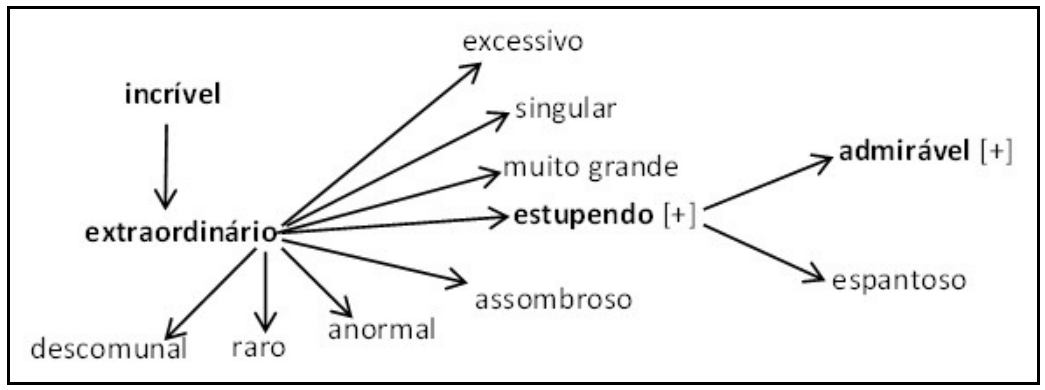

FIGURA 1 - Rede de palavras associadas a incrivel

Fonte: Elaboração própria.

\subsection{Polaridade e prosódia semântica}

A atribuição de polaridade a palavras ou expressões também é compatível com a noção de prosódia semântica (PS). Surgida no contexto da linguística com corpus, especialmente na fraseologia, a PS está relacionada diretamente à ideia de naturalidade na linguagem - algumas combinações, ainda que bem formadas sintaticamente, podem não parecer "naturais", como seria o caso da produção de falantes não nativos de uma língua. Ou seja, a PS indicaria apenas uma preferência, e não uma obrigatoriedade. Além da naturalidade, a PS revela, por meio dos padrões de associação, atitudes favoráveis ou desfavoráveis que impregnariam combinações de palavras que normalmente ocorrem juntas. Uma combinação como ampliar o número de mortos/feridos é muito pouco provável, ${ }^{8}$

\footnotetext{
7 Idealmente, extraordinário também deveria remeter para incrível. Nesse caso, incrivel - associado a extraordinário - teria a marca [+].

${ }^{8}$ Vale notar que, em uma busca nos corpora do projeto AC/DC (Acesso a Corpus/ Disponibilização de Corpus, cf. seção 2.3), há diversas ocorrências de elevar|aumentar|crescer|subir o número de mortos/feridos, em que os verbos usados na busca podem ser considerados sinônimos de ampliar. Curiosamente, há uma única ocorrência de ampliar, mas com viés positivo, já que se fala de "mortos beneficiados": "par=FSP950830-374: Uma delas tem o objetivo de ampliar o número de mortos beneficiados com a indenização." Para efetuar a concordância, a expressão de procura foi [pos="V"] "o" "número" "de" [word="mortos|feridos"]
} 
assim como ampliar as dificuldades; ampliar as criticas ou ampliar a tristeza, porque ampliar tende a se associar a palavras "positivas" - diz-se que ampliar tem prosódia semântica positiva ${ }^{9}$ - ainda que, nos dicionários consultados, não haja qualquer menção a essa característica.

Como usual na metalinguagem relacionada ao significado, o conceito de PS tem sido usado de diferentes maneiras, com diferentes nuances, algumas inclusive discordantes entre si (HUNSTON, 2007). Não é o objetivo deste trabalho, no entanto, problematizar a noção de PS, e por isso o foco está na atribuição de atitudes/pontos de vista, positivos ou negativos, em contexto, a partir de corpus.

$\mathrm{Na}$ elaboração do léxico, assumimos que a atribuição de polaridade às palavras não pode ser isolada do ponto de vista. Admitir que algo pode ser intrinsecamente bom ou ruim é incompatível com as posições defendidas quanto ao significado. Assim, é razoável supor que frequentemente não existe uma interpretação indisputável. O verbo reconhecer, por exemplo, evidencia a concordância com uma proposição que vai contra um ponto de vista mais geral. No exemplo adaptado de Hunston (2007), "X é talvez o primeiro historiador branco a reconhecer que sem as armas de fogo, a África poderia não ter sido escravizada", infere-se, a partir da escolha pelo verbo reconhecer, que quem narra o fato acha que as armas de fogo contribuíram para a escravidão da África,

${ }^{9}$ Outros exemplos retirados do corpus Floresta, por meio da interface AC/DC:

(1) Além disso, o ANC vai reter e até ampliar as suas infra-estruturas militares e prosseguirá também com a sua campanha contra a violência.

(2) Agora vamos ampliar a nossa oferta para os ambientes empresariais com o Digital Unix, que é um dos melhores Unix do mercado.

(3) Ampliando suas atividades ao publico, o Museu da Imagem e do Som de Sao Paulo promove oficinas nas áreas de cinema, vídeo, fotografia, novas tecnologias, marketing cultural, som e grafite.

(4) Nos últimos dias, o Banco Nacional de Desenvolvimento Econômico e Social (BNDES) passou a ampliar o foco de sua atuação, ajudando a organizar fundos de investimento em empresas emergentes com potencial tecnológico.

(5) Dois ótimos novos procuradores da Internet que ampliam as opções do Google:

(6) A IBM, maior empresa de informática do mundo, está ampliando sua atuação no mercado financeiro brasileiro.

(7) Lufthansa amplia oferta de vôos para Munique.

(8) E o FC Porto acabou mesmo por ampliar a vantagem, muito por culpa de Eduardo Filipe, Ricardo Costa e Rui Rocha, um trio que só à sua conta somou 12 golos. 
diferentemente do autor do discurso relatado na frase, "X". No entanto, embora o exemplo ilustre a presença de opinião e de posicionamento, este é difícil de ser enquadrado em termos de polaridade positiva ou negativa. E, por isso, esse tipo de construção não integra, até o momento, o léxico criado.

\subsection{Polaridade, emoção e sentimento}

$\mathrm{Na}$ tradição ocidental, encontramos formulações a respeito da afetividade desde Platão, que conceitua emoção, cognição e conação. Atualmente, o tema interessa a áreas distintas, da antropologia à inteligência artificial, cada uma com seus desafios e suas respostas. A multiplicidade de olhares e interesses leva, naturalmente, à diversidade de nomenclaturas somando-se à dificuldade intrínseca de tratamento de um tema com dimensões e desdobramentos culturais, cognitivos, filosóficos e linguísticos (veja-se Longhi [2011] para uma descrição detalhada das diferentes abordagens para o estudo das emoçóes).

Utilizo, neste trabalho, a palavra afetividade para caracterizar o léxico, termo usado para fazer referência à vivência de sentimentos positivos ou negativos. Dado o amplo escopo da afetividade, e o caráter inicial da exploração, a observação foi reduzida a uma das dimensões afetivas da linguagem: a polaridade. A polaridade, por sua vez, perpassa as emoções: considerando, por exemplo, as chamadas "emoções básicas" propostas em Ekman (1999) - medo, raiva, tristeza, alegria, surpresa, aversão - percebemos que, se alegria é uma emoção cuja polaridade é positiva, e raiva e tristeza são regularmente associadas a uma polaridade negativa, a emoção surpresa pode ser positiva (frases [1]-[2]), negativa (frases [3]-[4]), ou pode ter uma polaridade muito fraca, se alguma (frases [5]-[6]), como ilustram os exemplos retirados de corpora que integram o projeto AC/DC - Acesso a corpos/Disponibilização de corpos (COSTA et al., 2009): ${ }^{10}$

(1) É impressionante, mas a tecnologia continua surpreendendo com uma velocidade como nunca se viu na história do homem.

(2) Me surpreendi com a qualidade de trabalhos que eu desconhecia.

(3) E Carlos Narciso junta a sua voz à aqueles que se surpreendem com do facto de Domingos Pereira, condenado a 15 anos pela morte da mulher, ter cumprido apenas seis.

${ }^{10}$ Os corpora estão disponíveis em: <http://www.linguateca.pt/ACDC>. 
(4) Já pensou, ser surpreendido com a morte de algum amigo?

(5) Não sei por que as pessoas ficam surpreendidas com o sucesso da nossa seleção.

(6) E o pessoal da terceira idade se surpreende com tudo.

Além da polaridade, e para dar conta também da aplicação proposta, consideramos, na compilação das entradas do léxico, a presença de opinião. Não é novidade, no entanto, a dificuldade em estabelecer as fronteiras entre o que é opinião e o que não é. Compatível com a visão não essencialista aqui assumida, que não opóe literal/denotativo ao figurado/conotativo, está a não oposição entre fato e julgamento, ou entre "verdade" e retórica (ARROJO, 1992 , p. 67). Isso porque a distinção pressuporia uma primeira etapa, um primeiro nível de relação entre sujeito/leitor e realidade/texto, "que pudesse ser objetivamente previsível e determinável, independentemente de uma perspectiva ou de um contexto." (p. 67). Não é possível negar, no entanto, a existência de enunciados muito mais fortemente - ou explicitamente carregados de opiniāo, como em "odiei aquele filme", que certamente interessa identificar, considerando a aplicação pretendida. Para dar conta dessa frágil distinção, nos apoiamos na solução adotada no processo de anotação do próprio corpus de resenhas de livros do qual o léxico deriva: para que uma frase fosse considerada alvo da anotação de opinião, deveria, de alguma maneira, responder à pergunta hipotética "gostou do livro/dessa parte do livro"? Assim, por exemplo, se a resposta dada à pergunta é "achei triste/é triste/a leitura é complexa”, não é possível saber se a pessoa gostou - e portanto, não é possível atribuir polaridade. Já se a resposta é “achei horrível/é horrível”, temos claramente uma opinião negativa. $\mathrm{O}$ mesmo procedimento foi adotado na seleção das entradas que comporiam o léxico. Para a pergunta "Gostou de X?", em que $\mathrm{X}$ pode ser um objeto, uma pessoa ou um evento, consideramos que as palavras/expressões do QUADRO 1 não respondem adequadamente à pergunta - e portanto não constam do léxico, ainda que possam apresentar alguma polaridade. Já as palavras/expressóes do QUADRO 2 respondem à pergunta, ainda que indiretamente. 


\section{QUADRO 1}

Palavras eliminadas do léxico de polaridades

ampliar[+]; confiar[+]; cumprir[+]; ganhar[+]; permitir[+]; responder[+]; superar[+];

faltar[-]; perturbar[-]; forçar[-].

Fonte: Elaboração própria.

\section{QUADRO 2}

Palavras que integram o léxico de polaridades

adorar[+]; agradar[+]; apreciar[+]; atrair[+]; conquistar[+]; curtir[+]; deliciar[+]; divertir[+]; emocionar[+]; empolgar[+]; fascinar[+]; fluir[+]; inovar[+]; recomendar[+]; sensibilizar[+]; simpatizar[+]; valorizar[+]; vibrar[+]; $\operatorname{viciar}[+]$;

aborrecer[-]; arrepender[-]; assustar[-]; atrapalhar[-]; cansar[-]; complicar[-]; decepcionar[-]; desistir[-]; detestar[-]; dificultar[-]; distorcer[-]; empacar[-]; enganar[-]; estragar[-]; estressar[-]; exagerar[-]; faltar[-]; frustrar[-]; incomodar[-]; irritar[-]; largar[-]; odiar[-]; pecar[-]; revoltar[-].

Fonte: Elaboração própria.

\section{A elaboração do léxico}

O léxico aqui apresentado foi derivado do corpus ReLi (FREITAS et al., 2012; 2013), composto por resenhas de livros publicadas na internet. O ReLi caracteriza-se por uma grande ocorrência de material expressivo e um uso variado de registros - tanto informal, típico da internet, quanto um pouco mais formal. Contém 1600 resenhas de treze livros (sete autores), totalizando cerca de 260 mil palavras e 12 mil frases. Para cada livro foram coletadas cerca de 200 resenhas e, quando esse número não pôde ser atingido, completamos com outras obras do mesmo autor até chegarmos a um número próximo a duzentos. $\mathrm{O}$ corpus foi automaticamente anotado com informação de classes de palavras e manualmente anotado quanto à expressão de opinião. No processo de anotação da opinião, foram marcadas (i) a polaridade da frase que expressa opinião; (ii) segmento(s) que expressa(m) a opinião; (iii) polaridade desses segmentos. ${ }^{11}$ Uma descrição detalhada do corpus, processo de anotação e teste interanotadores encontra-se em (FREITAS et al., 2012; 2013).

\footnotetext{
${ }^{11}$ Nem sempre a polaridade dos segmentos corresponde à polaridade geral da frase, como em "ainda que em alguns momentos a narrativa derrape, o livro é ótimo".
} 
A partir do corpus anotado, o primeiro passo foi extrair as sequências marcadas como núcleos de opinião, e agrupá-las segundo a classe gramatical. Em seguida, como nem todas as palavras núcleo expressam opinião (repleto, total, necessário etc.), foi feita, manualmente, uma seleção das candidatas a entradas. Além das palavras e expressóes, a análise do corpus permitiu também a elaboração de listas relacionadas à inversão de polaridade (estruturas negativas). As classes consideradas foram ADJ, V, N. Para cada classe, há uma lista de entradas com os lemas, obtidos automaticamente com o analisador morfossintático PALAVRAS (BICK, 2000), e polaridades. Expressões multivocabulares também integram o léxico.

$O$ processo de seleção das entradas, além de eliminar as palavras que não indicavam a presença de opinião e polaridade, se justifica principalmente pela preocupação em identificar palavras ou expressōes que, embora em um dado contexto sistematicamente apresentassem polaridade/opiniáo, faziam-no apenas no contexto específico de resenhas de livros. Por exemplo, imprevisivel, perturbador são características/açôes consideradas positivas no corpus (exemplos [7]-[8]), mas dificilmente o são em outros contextos. Por outro lado, pareceu interessante não dispensar as particularidades da qualificação nesse contexto. Assim, a opção foi por criar entradas separadas com elementos específicos do domínio cultural.

(7) O mais interessante é que o final foi imprevisivel e surpreendente.

(8) Sim, o final é ainda mais genial e perturbador!

A fim de obter mais segurança na análise das palavras e expressões, isto é, (i) confirmar que eram elementos que regularmente expressam afetividade e opinião; (ii) verificar se a polaridade expressa era geral ou específica de domínio, confrontamos as palavras das listas com as ocorrências nos diversos corpora do projeto AC/DC, especificamente no corpus Floresta, que contém textos jornalísticos e textos de blogs (FREITAS; SANTOS, 2013; AFONSO et al., 2001). A TAB. 1 apresenta a distribuição da entradas do léxico, por classe de palavra e por polaridade. Para cada entrada, estão disponíveis as informaçôes de lema, polaridade e classe de palavra. ${ }^{12}$

Dois critérios nortearam a incorporação de uma entrada no léxico. De acordo com o primeiro deles, mencionado na seção 2.3 , as palavras ou

${ }^{12} \mathrm{O}$ léxico está disponível em: <http://www.linguateca.pt/Repositorio/ReLi>. 
expressões candidatas deveriam conjugar a presença de polaridade e de opinião. De acordo com o segundo, deveriam, ainda, apresentar (relativa) estabilidade quanto ao tipo de polaridade (e, por isso, a importância da verificação em outros corpora). Além disso, quando um dado uso se restringia a um tipo de texto (especificamente, textos opinativos), optou-se por manter a entrada. Se, por outro lado, a polaridade/opinião flutuava sem permitir a identificação de qualquer regularidade, não.

O verbo sofrer é um bom exemplo. Em uma busca nos corpora do AC/ DC, embora apareça a tendência a ser acompanhado por palavras de polaridade negativa (ameaças, problemas, baixa, discriminação), o que permite considerálo um verbo de prosódia semântica negativa, há também uma quantidade considerável de ocorrências nas quais é difícil atribuir alguma polaridade, como em sofrer modificaçōes/mudanças/alteraçôes. No entanto, a construção sofrer para é usada regularmente para remeter algum tipo de dificuldade, de forma negativa do ponto de vista de quem relata. Assim, no léxico, consta apena a entrada sofrer para (sofri para terminar o livro, sofri para cancelar a compra, sofri para pedir um sanduiche etc.).

A próxima seção comenta alguns resultados da exploração das listas de polaridade e do corpus, conforme as classes de palavras. O APENDICE A apresenta exemplos das palavras que compóem o léxico.

\section{TABELA 1}

Distribuição das entradas do léxico, por classe e por polaridade

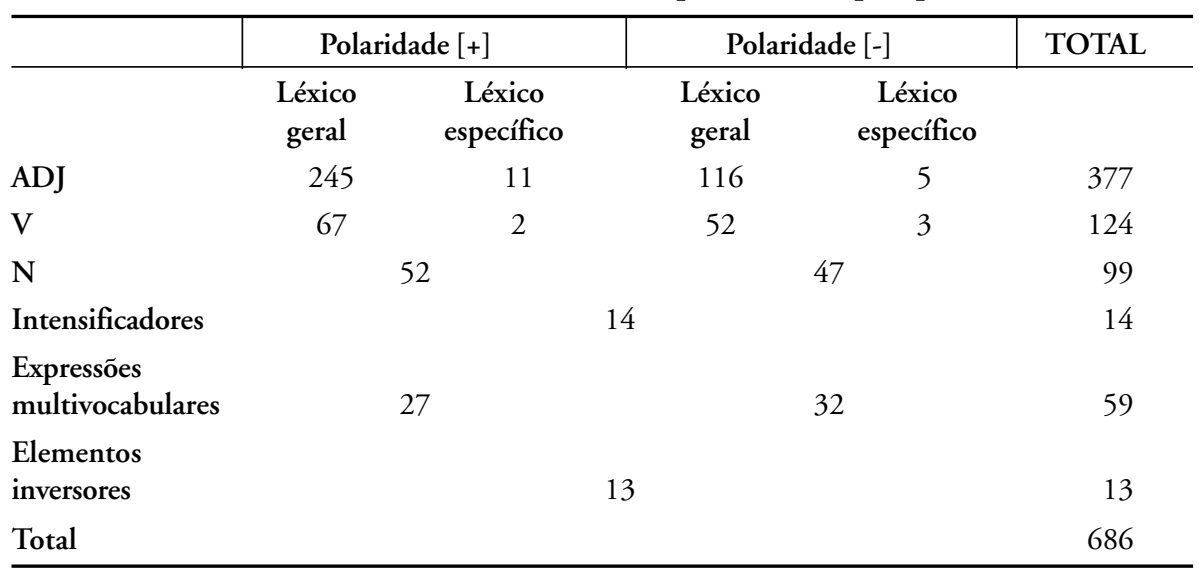

Fonte: Elaboração própria. 


\subsection{Adjetivos}

A maioria das abordagens para a identificaçăo de opinião baseadas em léxico privilegia adjetivos como indicadores da orientação semântica de um texto. No entanto, embora adjetivos sejam qualificadores por excelência, nem todos interessam a um léxico de polaridades - ou por terem um comportamento demasiado flutuante (por exemplo, comum), dependente do domínio ou do objeto qualificado (celular pequeno [+] vs. memória pequena [-]), ou pela dificuldade na própria atribuição da polaridade (triste em $O$ final da história é triste).

De um ponto de vista semântico, adjetivos podem ser descritores, isso é, atribuir propriedades, ou classificadores, cuja função principal é delimitar a expressão/entidade referida. Para a análise de opinião são relevantes os adjetivos descritores, que podem ainda se subdividir em diferentes classes semânticas, das quais interessa a classe avaliativa/emotiva, que inclui adjetivos como ruim, lindo, bom (BIBER et al., 1999, p. 509). No entanto, como nota Móia (1992), o comportamento semântico dos adjetivos está longe de ser homogêneo, e parece não haver propriedades distribucionais distintivas para as diferentes subclasses semânticas de adjetivos, mesma conclusão a que chega Rio-Torto (2006), quando afirma que as propriedades morfológico-sintáticosemânticas do adjetivo estão a serviço das diferentes modalidades de funcionamento e de interpretação do adjetivo. Por isso a relevância e necessidade de uma análise manual cuidadosa dos adjetivos.

$\mathrm{O}$ adjetivo arrasador, por exemplo, aparece como candidato à entrada positiva, pois suas ocorrências no corpus de resenhas indicam sistematicamente uma opinião favorável. A busca no AC/DC revela, no entanto, que embora arrasador seja usado com frequência para expressar pontos de vista favoráveis (um arrasador inicio de campeonato; a mais arrasadora personalidade feminina da Nova York; uma exibição arrasadora; um novo produto verdadeiramente arrasador), esse nem sempre é o caso - o que, aliás, está de acordo com as definiçōes lexicográficas de arrasar, que referem-se a destruição e devastação. No entanto, observamos que, no contexto dos objetos culturais, arrasador é sistematicamente usado de maneira positiva, como ilustram as ocorrências 9-12, retiradas do corpus Floresta do projeto $\mathrm{AC} / \mathrm{DC}$ :

(9) O livro é uma análise sofisticada e arrasadora do sistema político dos Eua no fim do século 19.

(10) O resultado: uma comédia arrasadora, onde a trama perde a importância frente à interpretação e a graça das falas. 
(11) Quem fecha o disco é o U2, com um arrasador remix de «Lemon».

(12) Em 90 minutos de um concerto arrasador, a musa do Carnaval da Baía mexeu, remexeu, rebolou, embalou, contagiando a multidão que encheu por completo o Coliseu da cidade.

Por isso, arrasador integra o léxico, mas em uma seção separada, com a indicação de que é um adjetivo com polaridade positiva em textos do domínio cultural. ${ }^{13}$

Alguns adjetivos, como infantil ou descritivo, podem ser descritores ou classificadores. No entanto, quando acompanhados de intensificadores, assumem uma polaridade negativa: muito infantil/muito descritivo; infantil demais/descritivo demais; totalmente infantil/totalmente descritivo. Essa informação está também no léxico, associada a regras, como ilustra a FIG. 2:

(a) [intensificador] descritivo/intelectual/juvenil/infantil/informal

(b) descritivo/intelectual/juvenil/infantil/informal [intensificador]

FIGURA 2 - Exemplo de entradas associadas a regras

Fonte: Elaboração própria

\subsection{Verbos}

No léxico, de modo semelhante aos adjetivos, os verbos foram separados em dois grupos: aqueles cuja polaridade é altamente estável, e aqueles cuja polaridade atribuída parece ter forte dependência do domínio/tipo de texto.

Além da propriedade predicadora dos verbos de relacionarem, pelo menos, dois argumentos, outro aspecto relevante no tratamento dos verbos diz respeito à diversidade de sentidos, que pode se refletir em diferentes polaridades.

O verbo arrebentar, embora sintaticamente dispense complemento nos exemplos (13) e (14), apenas em (14), utilizado em um registro informal, tem polaridade positiva:

${ }^{13}$ Uma outra solução seria indicar que arrasador tem polaridade positiva quando o argumento não é agente. No entanto, não temos, ainda, como fornecer descrição de papéis semânticos. 
(13) A corda sempre arrebenta do lado mais fraco.

(14) Aplauso para os caras que vieram do Acre e arrebentaram e a banda deles tá virando.

O verbo arrebentar, portanto, faz parte do léxico, mas integra a seção específica de domínio/registro. Dado o amplo uso em um registro informal com uma polaridade positiva regular, não há motivos para dispensar essa informação.

Outro exemplo interessante é o do verbo amadurecer. Embora, em termos gerais, seja difícil considerá-lo um verbo com polaridade, como ilustram os exemplos (15)-(18), retirados do corpus Floresta (AFONSO et al., 2001, [s. p.]):

(15) «Foi uma decisão muito ponderada, muito difícil e muito amadurecida», disse ao PÚBLICO Anabela Moutinho, que foi lacónica em o que se refere aos motivos.

(16) Ele se nega a sugerir em público uma data ideal, mas entende que a adesão à URV ainda tem o que amadurecer.

(17) Ele virá quando o país estiver amadurecido e sentir que entendeu as regras, que já não vamos fazer nenhuma injustiça aqui e ali e que é o momento de passar para o real.

(18) "Estamos amadurecendo hipóteses sobre as razões do maior sucesso no Pará", disse o pesquisador.

Quando tem como complemento entidades do domínio cultural, o verbo parece ser sistematicamente utilizado para expressar sentimentos positivos, indicando algum aspecto de melhoria e, consequentemente, a presença de uma opinião positiva, como ilustram (19)-(23), também retirados do corpus Floresta:

(19) A fórmula pop da Calypso amadureceu.

(20) É mesmo algo totalmente novo no gênero, que amadureceu esse tempo todo na cabeça e no sampler do DJ Sany Pitbull, o inventor das 5 faixas do novo EP.

(21) Além da já conhecida habilidade em criar tramas onde o riso predomina e em saber o que esperar de cada ator que escala, ele mostrou que sua escrita amadureceu, e não se restringiu à coletânea de piadas de gosto duvidoso exibidas em doses diárias de 45 minutos. 
(22) Nesse processo, amadureceram como artistas e se apropriaram de todos os truques pop que foram pilhando pelo caminho.

(23) Esse já é o $24^{\circ}$ trabalho cinematográfico de Cícero, que visivelmente amadureceu no trabalho e teve como reflexo a qualidade superior do filme.

O uso regularmente positivo de amadurecer corresponderia, de certa maneira, às acepçôes 4 e 5 de amadurecer segundo o Dicionário eletrônico Houaiss (v. 3.0), que expressam uma qualidade positiva, ainda que não esteja explicitado:

4 tornar mais elaborado, desenvolvido, acabado

Ex.: a. um projeto, uma ideia

5 tornar-se equilibrado, ponderado, sensato

Ex.: a relação do casal, a princípio caótica, acabou por a.

(HOUAISS, 2009).

Palavras mais diretamente associadas a sentimento também são um campo interessante para a exploração da afetividade na linguagem. $\mathrm{O}$ verbo apavorar, por exemplo, indica que aquilo que apavora é capaz de despertar o sentimento de medo. Mas não necessariamente o sentimento será negativo, como exemplifica (24), retirado do corpus ReLi, de uma resenha claramente positiva com relação ao livro:

(24) Este livro, para resumir, me apavorou. [...] O pavor vem, é claro, do envolvimento com a história [...]

Além disso, em contextos altamente informais, apavorar pode ser equivalente a ter um bom desempenho, e pode portanto ser usado de forma positiva, ao menos na variante brasileira do português, como ilustram os exemplos abaixo, retirados da internet e nos quais, conjugam-se polaridade positiva e opinião:

(25) Ele apavorou aqui em Brasília!!! Pra variar um pouquinho o Luiz Lima detonou aqui em Brasília na $4^{a}$ etapa do Brasileiro!!!! Invicto e com mais uma vitória!!!

(26) Depois de 400 fitas e muitos testes, achamos Zachary Weilandt, recomendação do fotógrafo Mark Weiss. Ele apavorou no teste.

(27) [...] e o mais legal foi a sua técnica com Slap, aí ele apavorou, foi realmente empolgante a velocidade e o bom senso musical do Tracy $[\ldots]$ 
Por fim, quanto aos verbos, vale lembrar que expressões multivocabulares verbais têm um comportamento mais previsível, e por isso compõem boa parte do léxico verbal. Se invejar, por exemplo, tem um comportamento de difícil formalização em termos de polaridade, a expressão de fazer inveja é usada regularmente em situaçóes positivas. No apêndice listamos expressões que constam do léxico, mesmo as que não contêm verbos.

\subsection{Negação e inversores de polaridade}

Em trabalhos relacionados à atribuição de polaridade, é fundamental considerar elementos de negação, dada a sua capacidade de inverter a polaridade de determinadas palavras ou expressões: não gostei é negativo, pois o não inverte a polaridade positiva de gostei. Mas nem apenas advérbios exercem a função de inversores. $\mathrm{O}$ adjetivo impossivel também pode funcionar como inversor (impossiveis de largarl impossivel abandonar o livro por a metade, em que abandonar e largar são verbos com polaridade negativa, e o inversor impossivel faz com que os trechos passem a indicar comentários favoráveis ao livro.).

Os exemplos acima ilustram dependência contextual e a impossibilidade de polaridades/atribuições estanques, assim como de significados estanques. A polaridade indicada nos itens do léxico revela o uso mais convencional, e busca refletir as generalizaçóes feitas pelos falantes do português. Sabemos, no entanto, do papel fundamental da criatividade na linguagem humana, ainda mais fortemente presente em contextos expressivos e opinativos. Por isso a importância do corpus, entendido como o espaço que simultaneamente reflete o uso convencional e fornece amostras do potencial criativo, nos confrontando com a impossibilidade de regularidades absolutas e comportamentos totalmente previsíveis.

\section{Considerações finais}

Apresentamos aqui algumas considerações relativas à construção de um léxico do português com elementos expressivos e polaridades associadas a partir da sua identificação em um corpus de resenhs de livros.

O processo de elaboração manual do léxico se justifica principalmente pela preocupação em eliminar as palavras que, embora em um dado contexto aparecessem como portadoras de polaridade/opinião, faziam-no apenas em contextos muito restritos. Adicionalmente, a existência de um léxico com elementos expressivos da língua portuguesa e polaridades associadas pode ser de 
grande valor também de um ponto de vista lexicográfico. Por isso, o processo de seleção das palavras não consistiu apenas na leitura e eventual descarte de algumas palavras ou expressões, mas incluiu a consulta a corpora diversificados, com o objetivo de observar o comportamento das palavras em diferentes contextos, e não apenas no âmbito de resenhas de livros publicadas na internet. Assim, o léxico foi criado com um duplo objetivo: fornecer subsídios para uma aplicação do PLN, nomeadamente a tarefa de análise de opinião, e contribuir para a caracterização do vocabulário expressivo da língua portuguesa, sobretudo em contextos informais.

A inexistência de dicionários para a linguagem expressiva dificulta a realização da tarefa do ponto de vista linguístico, ao mesmo tempo em que motiva a investigação sobre essa dimensão da linguagem. É sabido que o vocabulário de expressividade é de grande relevância para aqueles que desejam aprender uma língua. Por outro lado, ao menos com relação ao ensino de português, são escassos os recursos didáticos que atentam para esse aspecto tão humano da interação. A elaboração de dicionários para aprendizes, que incorporem esse tipo de informação é, portanto, uma atividade de grande relevância no contexto do ensino de línguas, e o presente trabalho busca também sensibilizar a comunidade de estudos da linguagem para esse aspecto do português, bem como lançar algumas sugestôes sobre como abordar a questão.

As palavras e expressōes do ReLi-Lex podem contribuir para a investigação, na língua, de outras dimensões semânticas, como as emoções. Palavras com polaridade têm, também, sentimento, embora nem sempre um dado sentimento esteja associado à mesma polaridade: um livro, filme ou enredo angustiante ou aterrorizante podem ser considerados bons, ainda que a angústia ou o terror não sejam, normalmente, sentimentos positivos. Assim, uma possibilidade futura é o estudo sobre como a polaridade dos sentimentos varia, em complementação ao que vem sendo feito por Maia e Santos (2012). Outro caminho a ser explorado é a incorporação de informação relativa à intensidade: algo que não é excelente é, necessariamente, ruim? Por fim, investigar em que medida a combinação de palavras com polaridades distintas pode indicar a presença de ironia também parece um caminho instigante. Do ponto de vista da descrição do português, espera-se que o trabalho possa contribuir para uma caracterização da classe semântica dos adjetivos avaliativos/ emotivos.

É interessante constatar que nosso léxico é bem mais enxuto que os relatados na literatura (SILVA et al. [2012], TABOADA et al. [2011] e o 
SentiWordNet, para citar alguns). Não consideramos, por exemplo, palavras com polaridade neutra, o que explica boa parte da diferença numérica. Por outro lado, um léxico maior e mais abrangente pode ser uma armadilha. Cada domínio ou área tem suas preferências discursivas e jargões, e dar conta de todos os casos talvez seja dar conta de nenhum. Aterrorizante, sufocante, surpreendente, imprevisivel, perturbador podem ser positivos para objetos culturais como filmes e livros, mas certamente não o são em outros domínios. Por isso, parece interessante a ideia de um léxico geral, enxuto, associado a léxicos-satélites, específicos de domínio, que podem ser construídos por demanda. No ReLi-Lex, as entradas cuja polaridade pareceu específica do domínio "livros" foram separadas.

Do ponto de vista do PLN, o desenvolvimento mais imediato é a investigação sobre formas automáticas ou semiautomáticas de expansão do léxico, fazendo uso de pistas léxico-sintáticas como a coordenação.

Do ponto de vista teórico, assumir uma perspectiva não essencialista com relação ao significado tem como desdobramento o reconhecimento de que qualquer palavra é capaz de encerrar uma carga expressiva que pode, inclusive, ser variável. No entanto, não há como negar regularidades no uso da língua em uma dada comunidade discursiva, e o léxico proposto tenta capturar tais regularidades no que se refere à expressividade. A intenção, assim, é revelar quais significados são selecionados em um dado momento em uma dada comunidade, já que interpretações semelhantes resultam de convençōes institucionalizadas. Entender o significado atribuído é, portanto, entender uma das faces das convençōes (GRIGOLETTO,1992, p. 95).

Deste modo, o léxico captura o que pode ser generalizado, as convenções, as estabilidades. Os usos particulares, por sua vez, permanecem no corpus, como exemplo da resistência; da criatividade no uso.

Quando se associa ao PLN, uma perspectiva não essencialista sobre a linguagem, que busca "construir generalizações que, se não são definitivas, buscam lançar alguma luz sobre nossas práticas linguísticas" (MARTINS, 1999, p. 144), se mostra produtiva na medida em que assume o auxílio à resolução de tarefas de sistemas que manipulam a língua como um objetivo tão legítimo quanto a compreensão do funcionamento da mente com relação à linguagem ou o ensino de línguas, por exemplo. Uma linguística que assume suas/as limitaçóes na busca por um conhecimento objetivo e verdadeiro parece a mais indicada para colaborar em uma área como o PLN, que precisa tanto do conhecimento linguístico quanto de flexibilidade na utilização desse 
conhecimento. Vale lembrar, por fim, que este conhecimento não deve, idealmente, ser limitado demais a ponto de resolver um problema de um único sistema, o que possivelmente acarretaria em um resultado de pouco interesse linguístico, ainda que com impacto do ponto de vista prático. A ideia é que a descrição seja motivada por uma aplicação, mas não subordinada a ela.

\section{Referências}

AFONSO, S. et al. Floresta sintá(c)tica: um treebank para o português. In: ENCONTRO DA ASSOCIAÇÃO PORTUGUESA DE LINGUÍSTICA, 17., out. 2001, Lisboa. Actas... Disponível em: <http://www.linguateca.pt/Diana/ download/AfonsoetalAPL2001.pdf>. Acesso em: 27 jul. 2013. Não paginado. ARROJO, R. A desconstrução do logocentrismo e a origem do significado. In: (Org.). O signo desconstruido. Campinas: Pontes, 1992. p. 41-46.

ATKINS, B. T. S. The Oxford Guide to Practical Lexicography. Oxford (UK): Oxford University Press, 2008.

BIBER, D. et al. Longman Grammar of Spoken and Written English. New York: Pearson Education, 1999.

BICK, E. The Parsing System "Palavras": Automatic Grammatical Analysis of Portuguese in a Constraint Grammar Framework. Aarhus: Aarhus University Press, 2000.

BIDERMAN, M. T. Teoria lingüistica (teoria lexical e lingüistica computacional). 2. ed. São Paulo: Martins Fontes, 2001.

CORPOS de português: Projecto AC/DC. Disponível em: <http://www. linguateca.pt/ACDC>. Acesso em: 27 jul. 2013.

CORPUS ReLi. Disponível em: <http://www.linguateca.pt/Repositorio/ReLi>. Acesso em: 27 jul. 2013.

COSTA, L.; SANTOS, D.; ROCHA, P. Estudando o português tal como é usado: o serviço AC/DC. In: Brazilian Symposium in Information and Human Language Technology (STIL 2009), 7., 8-11 set. 2009, São Carlos. Anais... Disponível em: <http://www.lbd.dcc.ufmg.br/colecoes/stil/2009/020.pdf>. Acesso em: 27 jul. 2013. Não paginado.

EKMAN, P. Basic Emotions. In: DALGLEISH, T.; POWER, T. (Ed.). The Handbook of Cognition and Emotion. Sussex: John Wiley \& Sons, 1999. p. 45-60. ELLIS, J. M. Language, Thought and Logic. Evanston: Northwestern University Press, 1993. 
ESULI, A.; SEBASTIANI, F. SentiWordNet: A Publicly Available Lexical Resource for Opinion Mining. In: INTERNATIONAL CONFERENCE ON LANGUAGE RESOURCES AND EVALUATION (LREC), 5., May 2006, Genoa. Proceedings... Disponível em: <http://www.lrec-conf.org/proceedings/ lrec2006/pdf/384_pdf.pdf>. Acesso em: 27 jul. 2013. p. 417-422.

EXTRAORDINÁRIO. In: Dicionário Priberam da Língua Portuguesa. Disponível em: <http://www.priberam.pt/dlpo/default.aspx?pal=extraordin\% C3\%A1rio >. Acesso em: 27 jul. 2013.

FELLBAUM, C. WordNet: An Electronic Lexical Database. Cambridge (MA): MIT Press, 1998.

FREITAS, C. et al. Sparkle Vampire... LoL! Annotating opinions in a book review corpus. In: ALUÍSIO, S.; TAGNIN, S. (Org.). 11th Corpus Linguistics Conference. Cambridge (UK): Cambridge Scholars Publishing, 2013. No prelo.

FREITAS, C. et al. Vampiro que brilha... rá! Desafios na anotação de opinião em um corpus de resenhas de livros. In: ENCONTRO DE LINGUÍSTICA DE CORPUS, 11., 2012, São Carlos. Anais... Disponível em: <http://www. linguateca.pt/Repositorio/ReLi/Anais_ELC2012_Freitasetal.pdf>. Acesso em: 27 jul. 2013. Não paginado.

FREITAS, C.; SANTOS, D. Blogs, Amazônia e a Floresta Sintá(c)tica: um corpus de um novo gênero? In: SARMENTO, S. et al. (Org.). Pesquisas e perspectivas em linguística de corpus. Campinas: Mercado de Letras, 2013.

GRIGOLETTO, M. A desconstrução do signo e a ilusão da trama. In: ARROJO, R. (Org.). O signo desconstruído. Campinas: Pontes, 1992. p. 31-34.

GUTHRIE, L. et al. The Role of Lexicons in Natural Language Processing. Communications of the ACM, v. 39, n. 1, p. 63-72, Jan. 1996.

HOUAISS, A. Dicionário eletrônico Houaiss da lingua portuguesa. Versão 3.0. Rio de Janeiro: Objetiva, 2009. 1 CD-ROM.

HUNSTON, S. Semantic Prosody Revisited. International Journal of Corpus Linguistics, v. 12, n. 2, p. 249-268, 2007. Disponível em: <http://www. researchgate.net/publication/228929277_Semantic_prosody_revisited $>$. Acesso em: 27 jul. 2013.

ILARI, R.; GERALDI, J. W. Semântica. São Paulo: Ática, 1985.

INCRÍVEL. In: Dicionário Priberam da Lingua Portuguesa. Disponível em: $<$ http://www.priberam.pt/dlpo/default.aspx?pal=incr\%C3\%ADvel>. Acesso em: 27 jul. 2013. 
LONGHI, M. T. Mapeamento de aspectos afetivos em um ambiente virtual de aprendizagem. 2011. 273 f. Tese (Doutorado em Informática na Educação) Centro de Estudos Interdisciplinares em Novas Tecnologias na Educação, Universidade Federal do Rio Grande do Sul, Porto Alegre, 2011. Disponível em: <http://pct.capes.gov.br/teses/2011/42001013075P9/TES.PDF>. Acesso em: 27 jul. 2013.

MAIA, B.; SANTOS, D. "Who's afraid of ... what?" - in English and Portuguese. Varieng - Studies in Variation, Contacts and Change in English, v. 12, 2012. Disponível em: <http://www.helsinki.fi/varieng/journal/volumes/12/ maia_santos>. Acesso em: 27 jul. 2013. Não paginado.

MARTINS, H. Metáfora e polissemia no estudo das línguas do mundo: uma aproximação não representacionista. 1999. 190 f. Tese (Doutorado em Linguística e Filologia) - Faculdade de Letras, Universidade Federal do Rio de Janeiro, Rio de Janeiro, 1999.

MARTINS, H. Três caminhos na filosofia da linguagem. In: MUSSALIM, F.; BENTES, A. C. (Org.). Introdução à Lingüistica. São Paulo: Cortez, 2004. v. 3, p. 439-474.

MOHAMMAD, S., DUNNE, C., DORR, B. Generating High-Coverage Semantic Orientation Lexicons From Overtly MarkedWords and a Thesaurus. 2009 CONFERENCE ON EMPIRICAL METHODS IN NATURAL LANGUAGE PROCESSING, 6-7 ago. 2009, Singapura. Proceedings... Disponível em: <http://www.cs.umd.edu/ cdunne/hcil/pubs/Mohammad09 Generatinghigh-coveragesemantic.pdf>. Acesso em: 27 jul. 2013. p. 599-608. MÓIA, T. Sobre classes semânticas de adjectivos. Cadernos de Semântica, Lisboa, v. 7, p. 1-34, 1992.

NIETZSCHE, F. W. Sobre verdade e mentira no sentido extra-moral. In: Obras incompletas/Friedrich Nietzsche. Seleção de textos de Gérard Lebrun; tradução e notas de Rubens Rodrigues Torres Filho. 4. ed. São Paulo: Nova Cultura, 1911 [1987]. (Os Pensadores).

OCHS, E.; SCHIEFFELIN, B. Language has a heart. Text-Interdisciplinary Journal for the Study of Discourse, v. 9, n. 1, p. 7-26, 1989.

PANG, B.; LEE, L. Opinion Mining and Sentiment Analysis. Foundations and Trends in Information Retrieval, v. 2, n. 1-2, p. 1-135, 2008.

RIO-TORTO, G. Para uma gramática do adjectivo. Alfa, São Paulo, v. 50, n. 2, p. 103-129, 2006.

SAMPSON, G. Empirical Linguistics. London: Continuum, 2001. 
SANTOS, D. et al. Relações semânticas em português: comparando o TeP, o MWN.PT, o Port4NooJ e o PAPEL. In: BRITO, A. M. et al. (Ed.). XXV Encontro Nacional da Associação Portuguesa de Linguística: Textos seleccionados. Associação Portuguesa de Linguística: Lisboa, 2010. p. 681-700. Disponível em: <http:// www.apl.org.pt/apl-actas/xv-encontro-nacional-da-apl.html>. Acesso em: 27 jul. 2013.

SILVA, M.; CARVALHO, C.; SARMENTO, L. Building a Sentiment Lexicon for Social Judgement Mining. In: Computational Processing of the Portuguese Language. 10th International Conference, PROPOR 2012, Coimbra, Portugal, April 17-20, 2012. Berlin: Springer Berlin Heidelberg, 2012. p. 218-228. (Lecture Notes in Computer Science, 7243).

TABOADA, M. et al. Lexicon-Based Methods for Sentiment Analysis. Computational Linguistics, v. 37, n. 2, p. 267-307, Jun. 2011. Disponível em: $<$ http://cgi.sfu.ca/-mtaboada/docs/Taboada_etal_SO-CAL.pdf>. Acesso em: 27 jul. 2013.

TAYLOR, T. Mutual Misunderstanding: Scepticism and the Theorizing of Language and Interpretation (Post-Contemporary Interventions). Durham; London: Duke University Press, 1992.

WILSON, T.; WIEBE, J.; HOFFMANN, P. Recognizing Contextual Polarity in Phrase-Level Sentiment Analysis. In: 2005 HUMAN LANGUAGE TECHNOLOGY CONFERENCE AND THE CONFERENCE ON EMPIRICAL METHODS IN NATURAL LANGUAGE PROCESSING, 2005, Vancouver. Proceedings... Disponível em: <http://www.cs.utexas.edu/ $\mathrm{ml} / \mathrm{HLT}$ EMNLP05>. Acesso em: 27 jul. 2013. p. 347-354.

WITTGENSTEIN, L. Investigaçôes filosóficas. São Paulo: Abril Cultural, 1979. (Os Pensadores). 


\section{APÊNDICE A - Entradas do léxico}

\section{SUBSTANTIVOS [+]}

[alegria]; [astúcia]; [atemporalidade]; [beleza]; [bem-estar]; [best-seller]; [brilho]; [carisma]; [clímax]; [companheirismo]; [compreensão]; [deleite]; [densidade]; [diferencial]; [diversão]; [doçura]; [emoção]; [empatia]; [entusiasmo]; [envolvente]; [êxtase]; [fã]; [facilidade]; [fascinação]; [favorito]; [fluência]; [fluidez];

[genialidade]; [gostinho]; [grandeza]; [inteligência]; [ironia]; [jóia]; [magnetismo]; [mérito]; [obra-prima]; [originalidade]; [paixão]; [perfeição]; [prazer]; [predileto]; [preferido]; [primor]; [sensibilidade]; [sufocamento]; [talento]; [taquicardia]; [ternura]; [top]; [virtude].
SUBSTANTIVOS [-]

[anticlímax]; [besteira]; [bobagem];

[boçal]; [bosta]; [chatice]; [clichê];

[decepção]; [defeito]; [demorar];

[desastre]; [desconforto]; [desesperança];

[desgraça]; [desprazer]; [droga]; [engano];

[erro]; [exagero]; [exaustão]; [excesso];

[falhar]; [falho]; [falta]; [furo];

[imaturidade]; [incômodo];

[inexperiente]; [lixar]; [meleca];

[melodrama]; [melodramático]; [meloso];

[monótono]; [mundo]; [nojo];

[passividade]; [pena]; [pieguice]; [porca];

[porcaria]; [problema]; [sacrifício];

[sentimentalismo]; [superficialidade];

[vergonha].

\begin{tabular}{|c|c|c|}
\hline & VERBOS [+] & VERBOS [-] \\
\hline Léxico geral & $\begin{array}{l}\text { [adorar]; [agradar]; [amadurecer]; } \\
\text { [amar]; [animar]; [apaixonar]; } \\
\text { [apegar]; [apreciar]; [aprender]; } \\
\text { [arrebatar]; [arrebentar]; [atrair]; } \\
\text { [cativar]; [conquistar]; [curtir]; } \\
\text { [deliciar]; [destacar-se]; [divertir]; } \\
\text { [emocionar]; [emplacar]; } \\
\text { [empolgar]; [encantar]; } \\
\text { [enternecer]; [entreter]; [facilitar]; } \\
\text { [fascinar]; [fluir]; [gostar]; } \\
\text { [identificar]; [inovar]; } \\
\text { [recomendar]; [sensibilizar]; } \\
\text { [simpatizar]; [valorizar]; [vibrar]; } \\
\text { [viciar]. }\end{array}$ & $\begin{array}{l}\text { [abandonar]; [aborrecer]; [arrepender]; } \\
\text { [assustar]; [aterrorizar]; [atormentar]; } \\
\text { [atrapalhar]; [cansar]; [chocar]; } \\
\text { [complicar]; [decepcionar]; [deprimir]; } \\
\text { [desanimar]; [desgastar]; [desistir]; } \\
\text { [desmerecer]; [destorcer]; [detestar]; } \\
\text { [dificultar]; [distorcer]; [empacar]; } \\
\text { [enfraquecer]; [enganar]; [engolir]; } \\
\text { [errar]; [estragar]; [estressar]; [exagerar]; } \\
\text { [faltar]; [frustrar]; [incomodar]; [irritar]; } \\
\text { [largar]; [limitar]; [odiar]; [pecar]; } \\
\text { [perder]; [prolongar]; [revoltar]. }\end{array}$ \\
\hline $\begin{array}{l}\text { Verbos com } \\
\text { polaridade } \\
\text { no âmbito } \\
\text { de objetos } \\
\text { culturais }\end{array}$ & $\begin{array}{l}\text { [apavorar]; [brilhar]; [comover]; } \\
\text { [devorar] } \\
\text { [prender]; [rir]; [saborear] } \\
\text { [surpreender]; [tocar]. }\end{array}$ & \\
\hline
\end{tabular}




\begin{tabular}{|c|c|c|}
\hline & ADJETIVOS [+] & ADJETIVOS [-] \\
\hline $\begin{array}{l}\text { Léxico } \\
\text { geral }\end{array}$ & $\begin{array}{l}\text { [admirável]; [adorável]; [agradável]; } \\
\text { [alegre]; [alucinante]; } \\
\text { [apaixonante]; [apoteótico]; } \\
\text { [ardente]; [arrasador]; } \\
\text { [arrebatador]; [astuto]; } \\
\text { [atemporal]; [aterrador]; [atraente]; } \\
\text { [atual]; [atuar]; [autêntico]; } \\
\text { [avassalador]; [bacana]; [bárbaro]; } \\
\text { [batuta]; [belíssimo]; [belo]; [bem]; } \\
\text { [bem-humorado]; [bom]; [bonito]; } \\
\text { [brilhante]; [carinhoso]; } \\
\text { [carismático]; [cativante]; [cativar]; } \\
\text { [certo]; [claro]; [classe]; [clássico]; } \\
\text { [coerente]; [comédia]; [cômico]; } \\
\text { [comovente]; [compreensível]; } \\
\text { [comum]; [consistente]; } \\
\text { [contagiante]; [contemporâneo]; } \\
\text { [contente]; [convincente]; } \\
\text { [corajoso]; [criativo]; [crivar]; } \\
\text { [curto]; [decente]; [delicado]; } \\
\text { [delicioso]; [demais]; [denso]; } \\
\text { [desafiador]; [despretensioso]; } \\
\text { [devanear]; [digno]; [dinâmico]; } \\
\text { [direto]; [distrativo]; [divertido]; } \\
\text { [divino]; [doce]; [duro]; [elegante]; } \\
\text { [eletrizante]; [emocionante]; } \\
\text { [empolgante]; [encantador]; } \\
\text { [encantável]; [engenhoso]; } \\
\text { [engraçado]; [enigmático]; } \\
\text { [enriquecedor]; [envolvente]; } \\
\text { [especial]; [esperto]; [espetacular]; } \\
\text { [espirituoso]; [esplêndido]; [essa]; } \\
\text { [estonteante]; [excelente]; } \\
\text { [excepcional]; [excitante]; } \\
\text { [exemplar]; [extraordinário]; } \\
\text { [fabuloso]; [face]; [fácil]; [fama]; } \\
\text { [fantástico]; [fascinante]; } \\
\text { [fascinate]; [favorito]; [feliz]; } \\
\text { [fluente]; [fluido]; [foder]; [fofo]; } \\
\text { [forte]; [frenético]; [fundamental]; } \\
\text { [genial]; [gostoso]; [gotoso]; } \\
\text { [grande]; [grandioso]; [gratificante]; } \\
\text { [impecável]; [imperdível]; }\end{array}$ & $\begin{array}{l}\text { [aborrecente]; [água-com-açúcar]; } \\
\text { [anacrônico]; [besta]; [bestar]; [bizarro]; } \\
\text { [bobo]; [burro]; [cansativo]; [chato]; } \\
\text { [chocante]; [chulo]; [clichê]; [confuso]; } \\
\text { [construir]; [decepcionante]; } \\
\text { [defeituoso]; [deplorável]; [depressivo]; } \\
\text { [deprimente]; [desagradável]; } \\
\text { [desconexo]; [desgastante]; } \\
\text { [desinteressante]; [desnecessário]; } \\
\text { [desprezível]; [difícil]; [dispensável]; } \\
\text { [doentio]; [egoísta]; [enfadonho]; } \\
\text { [enjoado]; [enjoativo]; [entediante]; } \\
\text { [esdrúxulo]; [estereotipado]; [estranho]; } \\
\text { [falsar]; [falso]; [fraco]; [frio]; } \\
\text { [frustrante]; [fútil]; [graça]; [horrível]; } \\
\text { [horroroza]; [idiota]; [idiotice]; } \\
\text { [imaturo]; [impaciente]; [impressionar]; } \\
\text { [incompreensível]; [inconsistente]; } \\
\text { [ingênuo]; [injustificável]; } \\
\text { [insuportável]; [interminável]; [inútil]; } \\
\text { [irritante]; [lamentável]; [maçante]; } \\
\text { [machista]; [mal]; [manjado]; [massa]; } \\
\text { [mau]; [mediano]; [médio]; [meloso]; } \\
\text { [mero]; [modinha]; [monótono]; } \\
\text { [morno]; [negativo]; [normal]; } \\
\text { [obsessivo]; [óbvio]; [oco]; [opressivo]; } \\
\text { [paranóico]; [patético]; [pesaroso]; } \\
\text { [péssimo]; [piegas]; [piorar]; [plana]; } \\
\text { [pobre]; [pomposo]; [preguiçoso]; } \\
\text { [previsível]; [puritano]; [rasa]; [raso]; } \\
\text { [razoável]; [reacionário]; [reclamo]; } \\
\text { [repa]; [repetitivo]; [repulsivo]; } \\
\text { [revoltante]; [ridículo]; [ruim]; [sem]; } \\
\text { [simplista]; [sofrível]; [superficial]; } \\
\text { [surreal]; [tédio]; [tedioso]; [tenda]; } \\
\text { [tongo]; [tosco]; [triste]; [vazio]; } \\
\text { [violento]; [volúvel]; }\end{array}$ \\
\hline
\end{tabular}




\begin{tabular}{|c|c|c|}
\hline & ADJETIVOS [+] & ADJETIVOS [-] \\
\hline & $\begin{array}{l}\text { [importante]; [impressionante]; } \\
\text { [inabalável]; [inacreditável]; [incrível]; } \\
\text { [indescritível]; [indispensável]; } \\
\text { [inédito]; [inesquecível]; [infalível]; } \\
\text { [inovador]; [inquietante]; [inquieto]; } \\
\text { [inspirador]; [instigante]; [instingar]; } \\
\text { [inteligente]; [intenso]; [interessante]; } \\
\text { [íntimo]; [intrigante]; [irado]; [irônico]; } \\
\text { [irresistível]; [jovial]; [legal]; [legítimo]; } \\
\text { [leve]; [liça]; [light]; [linda]; [lindo]; } \\
\text { [lírico]; [mágico]; [magistral]; } \\
\text { [magnético]; [magnificar]; [magnífico]; } \\
\text { [majestoso]; [maravilha]; [maravilhoso]; } \\
\text { [marcante]; [massa]; [máximo]; } \\
\text { [melífluo]; [memorável]; [minucioso]; } \\
\text { [misterioso]; [moderno]; [notável]; } \\
\text { [novo]; [obra]; [ode]; [original]; } \\
\text { [ótimo]; [palpável]; [passável]; } \\
\text { [perfeito]; [pertinente]; [plausível]; } \\
\text { [poderoso]; [poético]; [pontual]; } \\
\text { [positivo]; [precioso]; [predileto]; } \\
\text { [primo]; [primoroso]; [profético]; } \\
\text { [profundo]; [pungente]; [rápido]; } \\
\text { [raro]; [razoável]; [real]; [realista]; } \\
\text { [realístico]; [recente]; [recomendar]; } \\
\text { [recomendável]; [reflexivo]; [relaxante]; } \\
\text { [relevante]; [rico]; [sagaz]; } \\
\text { [satisfatório]; [seco]; [sedutor]; } \\
\text { [seguro]; [sensacional]; [sensível]; } \\
\text { [sensual]; [sentimental]; [sério]; [sexy]; } \\
\text { [significativo]; [simples]; [sincero]; } \\
\text { [singelo]; [singular]; [sólido]; [sublime]; } \\
\text { [subversivo]; [surpreso]; [surreal]; } \\
\text { [teres]; [tocante]; [tranqüilo]; } \\
\text { [translúcido]; [último]; [válido]; } \\
\text { [verdadeiro]; [verossímil]; [vertiginoso]; } \\
\text { [viciante]; [vicioso]; [vigoroso]; } \\
\text { [visceral]; [vital]; [voraz]. }\end{array}$ & \\
\hline $\begin{array}{l}\text { Adjetivos } \\
\text { com } \\
\text { polaridade } \\
\text { no âmbito } \\
\text { de objetos } \\
\text { culturais }\end{array}$ & $\begin{array}{l}\text { [arrasador]; [aterrorizante]; } \\
\text { [assustador]; [angustiante] } \\
\text { [compulsivo]; [frenético]; } \\
\text { [imprevisível]; } \\
\text { [surpreendente]; [sufocante]; } \\
\text { [perturbador]; [sombrio]. }\end{array}$ & $\begin{array}{l}\text { [estático]; [idêntico]; [lento]; [linear] } \\
\text { [óbvio]. }\end{array}$ \\
\hline
\end{tabular}


Léxico geral [abrir (a) mente]; [amor à primeira vista]; [arrancar lágrimas/ risadas/ gargalhadas]; [capturar a atenção]; [chamar a atenção]; [com chave de ouro]; [dar certo]; [de corpo e alma]; [de encher os olhos]; [de fazer inveja]; [de tirar o fôlego]; [deixar de boca aberta]; [[estar louco para]; faltar adjetivos ]; [faltar palavras]; [fazer pensar]; [fora de série]; [gostinho de quero mais]; [grata surpresa]; [ir a nocaute]; [lindo de morrer]; [morrer de rir]; [não ter adjetivos para]; [pra ninguém botar defeito]; [ser (um) show]; [ser um achado]; [ser um tapa na cara]; [soco na boca de o estômago]; [ter fôlego]; [tudo de bom]; [valer cada N]; [valer a pena]. [água com açúcar]; [cabeça-dura]; [carregar nas tintas]; [dar náuseas]; [dar raiva]; [dar sono]; [deixar a desejar]; [embrulhar o estômago]; [esperar mais]; [forçar a barra]; [mala sem alça]; [melhor esquecer]; [não aturar]; [não engolir]; [não prestar]; [não se enxergar]; [perder o fôlego]; [picolé de chuchu]; [pra criancinha]; [quebrou o encanto]; [sem graça]; [sem sal]; [sem-noção]; [ser um balde de água fria]; [ser um saco]; [tempo perdido / perder tempo/perda de tempo]. 